\title{
Continuing Science and Technology at the Proposed Yucca Mountain Repository
}

\author{
Dr. Robert J. Finch \\ Senior Science Advisor \\ Office of Civilian Radioactive Waste Management \\ Office of Science and Technology and International \\ U.S. Department of Energy
}

Yucca Mountain, Nevada, was designated in 2002 to be the site for the nation's first permanent geological repository for spent nuclear fuel and high-level radioactive waste. The process of selecting a site for the repository began nearly 25 years ago with passage of the Nuclear Waste Policy Act in 1982. The Department of Energy (DOE) is responsible for submitting a license application to the Nuclear Regulatory Commission for constructing and operating the repository, and DOE's Office of Civilian Radioactive Waste Management (OCRWM) is charged with carrying out this action. The use of multiple natural and engineered barriers in the current repository design are considered by OCRWM to be sufficiently robust to warrant license approval; however, potential design enhancements and increased understanding of both natural and engineered barriers, especially over the long time frames during which the waste is to remain isolated from human contact continue to be examined. The Office of Science and Technology and International (OST\&I) was created within OCRWM to help explore novel technologies that might lower overall costs and to develop a greater understanding of processes relevant to the long-term performance of the repository. A brief overview of Yucca Mountain, and the role that OST\&I has in identifying technological or scientific advances that could make repository operations more efficient or performance more robust, will be presented. It is important to note, however, that adopting any of OST\&I's technological or scientific developments will be at the discretion of OCRWM's Office of Repository Development (ORD). 